\title{
NARRATIVAS SOBRE O HALLEL A PARTIR DO JORNAL O DIÁRIO DO NORTE DO PARANÁ (MARINGÁ, 1995-2017)
}

\section{Narratives about Hallel from o Diário do Norte do Paraná newspaper (Maringá,} 1995-2017)

\author{
Vanda Fortuna Serafim ${ }^{1}$ \\ Mariane Rosa Emerenciano da Silva ${ }^{2}$
}

\begin{abstract}
RESUMO: O Hallel de Maringá é um evento de música católico, realizado anualmente na cidade de Maringá no norte paranaense desde 1995, pelo movimento leigo Projeto Mais Vida. $\mathrm{O}$ evento que acontece num final de semana reúne diversas pastorais e seguimentos da Igreja Católica que realizam pregações, palestras, teatros, missas e shows, como mecanismos de evangelização. Como principal fonte de análise para esse trabalho utilizamos o jornal local $O$ Diário do Norte do Paraná (1974-2019), que possuía uma circulação diária na cidade. As fontes indicam que o evento foi inspirado no Rock in Rio (1985), tendo a sua primeira edição foi idealizada na cidade de Franca-SP, em 1988, espalhando-se posteriormente para outras cidades do Brasil e do mundo. Em Maringá, a primeira edição ocorreu em 1995. Considerando que um dos intuitos do Hallel é promover o diálogo entre os jovens e a fé católica, por meio da realização de um evento inspirado no Rock in Rio, operacionalizaremos aqui, o conceito de "tradução" (HARTOG, 1999) a fim de visualizar o Hallel como um grande evento de música, com caráter evangelizador. Para tanto, iremos abordar como as narrativas sobre o Hallel de Maringá se assemelham ao que François Hartog (1999) define como "maravilhoso", ou seja, a busca por cativar os leitores sobre aquilo que está a ser narrado.
\end{abstract}

Palavras-chaves: Hallel; Jornais; catolicismo.

ABSTRACT: The Hallel of Maringá is a catholic music event, annually performed in the city of Maringá in northern Paraná, by the lay movement Projeto Mais Vida [Project More Life]. The event that happens in a weekend reunites a diversity of ministries and other Catholic Church bodies that carries out preaching, lectures, theatre plays, masses and concerts, as mechanisms of evangelization. As the principal source of analyses for this article was used the local newspaper O Diário do Norte do Paraná [The Diary of Northern Paraná] (1974 - 2019), which had a daily flow in the city, in the face of research undertaken through journals we observed a repetition in the articles that indicates it was inspired in Rock in Rio (1985), the first edition was idealized in the city of Franca-SP in 1988 and from 1995 on get editions in other cities. Considering the attempt of attracting the young to participate on the event in the city we identified that thinking the Rock in Rio as the inspirational event can be seen as a way of "translation" for visualizing the Hallel as a big music event, although with an evangelizing nature. To do so, in this article we will look to approach how the Hallel narratives from Maringá resemble what François Hartog (1999) define as "wonderful", it is, the search for captive the readers about what is being narrated.

Keywords: Hallel; newspaper; catholicism.

\footnotetext{
${ }^{1}$ Doutora em História pela Universidade Federal de Santa Catarina (2013). Professora adjunta no Departamento de História e no Programa de Pós-Graduação em História da Universidade Estadual de Maringá. E-mail: vandaserafim@gmail.com

${ }^{2}$ Graduada em História pela UEM (2017). Mestranda em História pelo Programa de Pós-Graduação em História UEM. Membro do Laboratório de Estudos em Religiões e Religiosidades (LERR/UEM) E-mail: marianer.emerenciano@gmail.com

REVISTARELEGENSTHRÉSKEIA - 2019 - UFPR
} 


\section{Introdução}

O presente artigo visa compreender por meio do o jornal O Diário do Norte do Paraná (1974-2019) como as narrativas desse periódico constitui uma perspectiva do "maravilhoso", no que tange a realização do Hallel na cidade de Maringá que começa a ser organizado na cidade no ano de 1995. É necessário pontuar que o Hallel é um evento de música católico que surge na cidade de Franca-SP no ano de 1988, idealizado inicialmente pela Renovação Carismática Católica $(\mathrm{RCC})^{3}$.

A partir de 1995 começa a ser organizado em outras cidades tais como Brasília-DF, Aparecida do Norte-SP e Maringá-PR, paulatinamente o Hallel se espalha para outras cidades, entretanto cada cidade organiza de maneira independente desde que haja autorização da diocese que circunscreve a cidade que pretende organizar o evento. Apesar do Hallel ser realizado em outras cidades e possuírem semelhanças como a apresentação dos shows de músicas gospel e a distribuição de "módulos", cada cidade que realiza o evento possuem suas particularidades, diante disso, ressaltamos que nosso objeto de análise se delimita ao Hallel de Maringá.

De circulação diária em Maringá O Diário do Norte do Paraná foi publicado de 1974 a abril de 2019, esse foi um dos jornais de maior expressividade na cidade, assim, O Diário se tornou uma das principais fontes escritas a que tivemos acesso sobre o Hallel de Maringá. Durante a análise do material notamos a presença demarcada da instituição católica nas matérias referentes ao objeto em questão, todavia, pensar nesses discursos é também pensar sobre quem enuncia, para quem enuncia e como é construído uma narrativa a que os leitores possam atribuir sentido.

Segundo Heloisa de F. Cruz e Maria do R. da C. Peixoto (2007), a imprensa é uma força ativa da vida moderna. Sendo assim é necessário pensar os jornais enquanto atuantes: no fomento à adesão ou ao dissenso, mobilizando para ação; na articulação, e divulgação e disseminação de projetos ideias, valores, comportamentos; na produção de referências homogêneas e cristalizadas para memória social; pela repetição e naturalização do inusitado no cotidiano, produzindo o esquecimento; na formação de visão imediata de realidade e de mundo (CRUZ; PEIXOTO, 2007, p. 259). Ao pensar nas questões apontadas pelas autoras, não

\footnotetext{
${ }^{3}$ Atualmente o Hallel de Franca é realizado pela ONG Hallel Escola. Vide: ALVES, André Luis Centofante. A gestão social na atividade educacional religiosa: o caso da Hallel Escola no Brasil. 2016. $201 \mathrm{f}$. Tese (Doutorado em Serviço Social) - Faculdade de Ciências Humanas e Sociais, Universidade Estadual Paulista "Júlio de Mesquita Filho", Franca, 2016.
} 
podemos deixar de considerar que as narrativas de lideranças católicas são constantes no $O$ Diário, o primeiro arcebispo da cidade Dom Jaime escrevia artigos de opinião dominicalmente para o jornal ${ }^{4}$. E os arcebispos posteriores ativamente se pronunciavam por esse veículo de comunicação. Além disso, até o ano de 2018 O Diário foi um dos apoiadores midiáticos do Hallel de Maringá.

Diante disso, observamos um discurso que vai ao encontro do que François Hartog (1999) aponta como "Thôma", ou seja, a narrativa do "maravilhoso". Como narrar por meio dos jornais um evento que diversos indivíduos ainda não haviam visto? Como "traduzir" o evento? Como apresentar o Hallel como um evento diferente e que atraia participantes? Ao nos referirmos sobre a narrativa do "maravilhoso" não podemos deixar de identificar que para além de uma "tradução" dos aspectos que inspiraram o evento, o Hallel é também um evento que possibilita a experiência de algo "fascinante" e "misterioso" que é o sagrado, no qual partimos de Rudolf Otto (1992). Para tanto, delimitaremos nosso recorte temporal de 1995 ano que é realizado o primeiro Hallel em Maringá e publicado as primeiras matérias sobre o evento até 2018, último ano em que o jornal circulou concomitante ao evento.

\section{Realização do Hallel em Maringá}

A fim de situar o Hallel, comecemos por explicar que, a cidade de Maringá foi fundada em 10 de maio de 1947, está localizada no Norte do Paraná e, segundo o último censo do IBGE/2010, possui uma estimativa populacional de 357. 077 habitantes ${ }^{5}$. Ao pensar na constituição religiosa da cidade de Maringá, observa-se a presença dominante e significativa do catolicismo. O censo aponta que 231.033 maringaenses se declaram Católico Apostólico Romano o que equivale a $65 \%$ da população maringaense que se auto declaram católica. Tal presença católica pode ser vista por diversos elementos na cidade de Maringá, desde um dos principais monumentos da cidade a Catedral de Nossa Senhora da Glória, aos movimentos de leigos, encontros e festividades religiosas católicas.

É nesse cenário que ocorre, anualmente, o Hallel, um evento de música que reúne várias pastorais e movimentos da Igreja Católica, realizado desde 1995 pelo movimento leigo Projeto Mais Vida (1992- presente). Esse grupo da Igreja Católica organiza acampamentos religiosos

\footnotetext{
${ }^{4}$ BARBOSA, Everton; PEÑA, Luciana. Jaime uma história de fé e empreendorismo. DNP Editora, Maringá, 2011.

${ }^{5}$ IBGE. Censo demográfico 2010: Disponível em: https://cidades.ibge.gov.br/brasil/pr/maringa/panorama. Acesso em: 11 de out, de 2019.
} 
para pessoas acima de 21 anos, além de realizar encontros semanais no Centro Catequético da Arquidiocese de Maringá, em que participam da "adoração ao Santíssimo", realizam partilhas, oram, cantam. Assim, desde 30 de julho de 1995 com apoio da Arquidiocese de Maringá o grupo é responsável pela organização do Hallel em Maringá, a última edição foi realizada em 05 e 06 de outubro de 2019 totalizando 25 edições do evento na cidade.

Durante um final de semana, pastorais e vários seguimentos da Igreja são convidados a evangelizar por meio do teatro, da música, da dança, da arte, palestras e orações. Quem entra pelo Pavilhão Azul do Parque de Exposição de Maringá nas datas em que são realizadas o evento, se depara com vários grupos de jovens, e pessoas de diversas idades que circulam entre a praça de alimentação, os estandes (para venda de artigos religiosos, de congregações religiosas $^{7}$, grupos leigos religiosos e dos patrocinadores ${ }^{8}$ ) e principalmente entre os módulos. Dispostos ao longo do parque, os módulos evangelizadores podem ser alterados entre uma edição e outra, dentre eles podemos citar: Hallelzinho, RCC, Família, Acampamento, Jovens, Arte, Pregadores, Confissão, Namoro, Maria, Capela do Silêncio, Capela do Louvor e Palco Central. Cada um desses módulos apresenta temáticas próprias que propõe um diálogo entre debates que perpassam o cotidiano dos indivíduos na contemporaneidade (namoro, fé, família, drogas, sexualidade) e a prática católica.

O Hallel tem como, um de seus grandes destaques, as atrações musicais do cenário católico. Em 25 edições, já passaram pelo Palco Central bandas e cantores como Martin Valverde, Daniel Poli, Ziza Fernades, Banda Dominus, Rosa de Saron, Banda Eterna, Cantor Boy, Raio de Luz, Cristoatividade, Luiz Alfredo, Luis Ascoy, Suely Façanha, Adriana, Anjos de Resgate, Pe. Fábio de Melo, Eugênio Jorge, Wilson Rocha, Dalvimar Gallo, Pe. Zezinho, Pe. Reginaldo Manzotti, ElectroCristo, Estância Divina, Polyana Demori, The Flanders, Cerimonya, Thiago Brado, Coral Arquidiocesano de Maringá, Gracielle, Andréia Salles, Mistério da Adoração, Colo de Deus, Pe. Periquito, Pe. Marcelo Rossi. Na maioria das edições

\footnotetext{
${ }^{6}$ A "adoração ao Santíssimo" é um dos ritos da Igreja católica realizada fora da missa afim de adorar Jesus Cristo presente no santíssimo Sacramento, ou seja, na Eucaristia. A adoração pode ser realizada tanto diante da Eucaristia conservada em um tabernáculo quanto exposta a adoração pública, nesse último caso geralmente exposto em ostensório. Ao se tratar das "exposições breves do Santíssimo Sacramento devem organizar-se de tal modo que nelas, antes da bênção, se consagre um tempo conveniente à leitura da Palavra de Deus, a cânticos, a preces e à oração em silêncio prolongada por algum tempo" (SAGRADA CONGREGAÇÃO PARA O CULTO DIVINO, 2000, p.77).

${ }^{7}$ Beneditinos, Franciscanos, Copiosa Redenção, Seminário Diocesano de Maringá, entre outros.

${ }^{8} \mathrm{O}$ evento tem apoio de Instituições, como a Arquidiocese de Maringá, a Prefeitura Municipal de Maringá, a Sociedade Rural de Maringá e o Hallel de Franca.
}

REVISTARELEGENSTHRÉSKEIA - 2019 - UFPR 
o evento começa no sábado, entretanto as atividades acontecem de forma mais intensiva no domingo, com o início da Santa Missa e o término com a Benção do Santíssimo.

Segundo os primeiros coordenadores do Hallel de Maringá, Olavo Araújo Carvalho Junior e Lincoln Preiss, no primeiro ano em que organizaram o evento, estimava-se um público de aproximadamente de 5.000 pessoas a serem abrigadas no Pavilhão Azul, do Parque de Exposição Francisco Feio Ribeiro - um dos principais locais para organização de eventos na cidade. Mas o número superou em muito a expectativa, alcançando aproximadamente 15.000 pessoas (ARAÚJO JR; PREISS, 2007, p.135). Desde então, o aumento de participantes foi contínuo, as estimativas demonstram que já na $3^{\text {a }}$ edição estavam presentes em torno de 30 mil participantes, em 2000 na $6^{\text {a }}$ edição haviam 60 mil, na 9a edição, 100 mil e, no ano posterior, 150 mil participantes, apesar dessa estimativa ter diminuído depois de 2014 é considerável a quantidade de pessoas que passam atualmente pelo Hallel que chega a ser aproximadamente 50 mil participantes ${ }^{9}$.

Ao pensarmos sobre essa prática católica na cidade de Maringá amplos debates sobre a Igreja católica e os leigos. Brenda Carranza e Cacília L. Mariz (2009) apontam dois momentos que corroboram para a compreensão de novas perspectivas na cultura cristã católica, principalmente no que consiste a atuação leiga.

Com a descristianização e a descatolização da sociedade em finais do século XIX, Leão XIII, na encíclica Rerum Novarum (1890) é proposto uma reorganização da base social do catolicismo. Segundo as autoras, florescem no século XX associais laicais e movimentos eclesiais, incorporando os leigos na retransmissão da tradição e na missão de evangelizar. Dessas agrupações proliferam no século XX, podem ser citados a Ação Católica, os Vicentinos, Cursilhos de Cristandades, Congregações Marianas. Nesse sentido, “com origens históricas e incidências socioeclesiais diferentes, esses movimentos se expandem com ênfase na participação do leigo (CARRANZA; MARIZ, 2009, p.140-141). Já no final da década de 1960, as CEBs e a Renovação Carismática Católica (RCC) surgem em contextos sociais diversos e inspirados de forma distinta pelo Vaticano II, “esses movimentos rompem com o modelo dos movimentos eclesiais acima citados na medida em que pretendem a transformação da Igreja Católica como um todo, redefinindo seja o tipo de atuação do leigo, seja na espiritualidade (CARRANZA; MARIZ, 2009, p.140-141).

\footnotetext{
${ }^{9}$ Dados levantados a partir do O Diário do Norte do Paraná. REVISTARELEGENSTHRÉSKEIA - 2019 - UFPR
} 
O primeiro movimento conhecido como novos movimentos está vinculado a um Código de Direito Canônico da Igreja, enquanto o segundo as novas comunidades, apesar de se assemelhar em vários aspectos ao catolicismo dos novos movimentos procuram manter sua autonomia e demarcar fronteiras em relação às comunidades paroquiais. Isso não significa que não possuem ou recebem a aprovação do bispo, na condição de associações de fiéis, na diocese onde foram fundadas (CARRANZA; MARIZ, 2009, p.143).

Destacamos tais questões, pois o Hallel reúne não apenas não apenas as novas comunidades católicas, como também os novos movimentos católicos, como por exemplo os Vicentinos e o os Cursilhos de Cristandade. Entretanto, a organização do evento é demarcada com maior ênfase nas práticas das novas comunidades católicas, principalmente no que tange as manifestações carismáticas como:

performática de danças, músicas, cantos e expressões corporais fizeram da oração e do louvor um elemento poderoso de atração dos fiéis oriundos de todas as camadas católicas, configurando um novo catolicismo de massas que apostava na cultura midiática como meio de reinstituição os afastados da Igreja (CARRANZA; MARIZ, 2009, p.140-141).

Segundo Marcelo Ayres Camurça (2009), dentro da Igreja o movimento da RCC foi o que melhor atendeu o chamamento papal para esse estilo de "nova evangelização" (CAMURÇA, 2009, p.64). A proposta de expansão do Hallel para outras cidades, a partir de 1995 ocorrera em consonância com essa nova proposta papal, tanto nas perspectivas em que envolve a evangelização através dos meios de comunicação quanto voltado para uma evangelização de um grande público com uma experiência individual e comunitária, fatores esses que dialogam com a "nova evangelização".

\section{Narrativas no o Diário do Norte do Paraná sobre o Hallel}

Na manhã de sábado, aos 29 dias de julho de 1995, uma matéria é publicada no O Diário se folhearem até a página 04 no Geral Burocrático o título da matéria é I Hallel de Maringá. A primeira pergunta que pode surgir é o que significa Hallel? E no primeiro parágrafo do texto tem-se a resposta: “A palavra 'HALLEL' é tirada de uma série de expressões bíblicas, sobretudo no Livro dos Salmos. Ela indica o sentido e a atitude do ser humano em relação ao Deus da Vida. Só Ele merece ser festejado com tudo aquilo que vive e respira" (O DIÁRIO DO NORTE DO PARANÁ, 1995, p. 4). Não há assinatura, não podemos indicar o autor e a notícia 
segue mencionando que o Hallel se tornou um fato, promovido pela Arquidiocese de Maringá para comunidade maringaense e regional. Nessa altura da leitura já é notável que se trata de um evento da Igreja Católica. As palavras continuam apontando que ao evento visa: "a articulação das forças vivas da Igreja, procurando levar as pessoas a olharem dentro de si e ver que aí habita Deus louco de amor e quanto cada pessoa pode ser amada e o quanto pode amar" (O DIÁRIO DO NORTE DO PARANÁ, 1995, p. 4). O que podemos ler depois são informações do que será apresentado no que denominam de Hallel:

O Hallel é uma festa que envolverá todas as pessoas de todas as faixas etárias das mais variadas formas. O evento acontecera no Parque de Exposições "Emílio Garrastazu Médici", com início às $9 \mathrm{~h}$, e término às $21 \mathrm{~h}$., no próximo dia 30, domingo que vem. O pavilhão coberto do coberto do parque será tomado nos seus dois ambientes por atividades diversificadas. No pavilhão maior ACONTECERÁ SHOWS com bandas profissionais de diversas partes do país, peças teatrais, danças, testemunhos de vida, pregações, etc. Simultaneamente, no pavilhão menor, terá palestra sobre família, drogas, auxílio ás famílias de dependentes químicos, evangelização, trabalhos "com os mais vividos" e um oratório para oração e reflexão.

O conjunto das atividades do Hallel Tenta responder aos grandes desafios por que passa a nossa população. Há pessoas, todos os dias, reclamando; pessoas depressivas; pessoas procurando sem saber o quê procuram; pais que não entendem seus filhos; filhos que não entendem seus pais; maridos traindo esposas; esposas traindo maridos... no fundo , no fundo, tudo isso acontece porque o individuo não entende a si próprio. Acaba se traindo e traindo o próximo porque se esquece que o centro dos problemas está no coração humano. Corações fechados estruturam-se em sistemas opressores e injustos, matando as pessoas no seu egoísmo.

O Hallel oferece VIDA. A Vida de Deus em cada coração humano. Oferece, também, a Graça de Deus, que é dom gratuito, transformando o homem "moderno" em "Nova Criatura", dando um novo sentido à sentido à sua existência, invertendo o centralismo do TER para o centralismo do SER (O DIÁRIO DO NORTE DO PARANÁ, 1995, p. 4).

A notícia articula as principais características do evento com destaque para a palavra "Shows". Além do mais a matéria atenta as problemáticas da contemporaneidade apontando como temas a serem abordados durante o evento, depressão, drogas, traição.

Na manhã seguinte, no dia em que estava sendo realizado o primeiro Hallel de Maringá, outra notícia sobre o evento é publicada essa possuí o título Hallel, escrita pelo então Arcebispo de Maringá na página 02 no setor de Opinião. Não era surpresa uma publicação de Dom Jaime já que publicava dominicalmente nesse jornal. O texto de Dom Jaime possuí elementos que se repetem em publicações posteriores sobre o Hallel; Franca-SP, Rock in Rio, evangelização e jovens. $\mathrm{O}$ arcebispo em seu texto argumenta que apesar da crescente onda de crimes, corrupção REVISTARELEGENS THRÉSKEIA - 2019 - UFPR 
nos meios governamentais ocasionado pelo afastamento de Deus levando a esse secularismo ainda há aqueles que para contrabalançar, existem:

aqueles que encontram Deus em sua vida não medem esforços para leva-lo, também, aos irmãos". São João, no Evangelho, diz que o "Espírito sopra onde quer" (Jo 3,8). E esse "soprar" do Espirito que faz crescer, no campo da Igreja, os diversos movimentos e maneiras de como falar com Deus. De como d'ELE se aproximar e de como tudo fazer para torna-lo conhecido. Uma vez conhecido, amado. Uma vez amado, fazer a sua Santíssima Vontade.

De modo especial, entre os JOVENS nasce um novo fervor apostólico e descoberta de Deus, da sua Igreja, do Senhor Jesus, "o mesmo ONTEM, HOJE e pelos SÉCULOS" (Hb 13,8), Aliás, o Papa João Paulo II, na Carta Tertio Millenio Adveniente, diz: "Se os jovens souberem seguir o caminho que Jesus indica, terão a alegria de dar o próprio contributo para a presença d' Ele no próximo século e nos sucessivos, até a conclusão dos tempos" (DOM JAIME, 1995, p. 2).

A carta a que Dom Jaime faz referência, escrita em 10 de novembro de 1994 pelo papa João Paulo II (1978-2005) propõe a preparação para o ano 2000, o Jubileu. O papa faz menções como deveria proceder a Igreja Católica no que ele chamava de "nova evangelização", que nasce da visão do Concílio Vaticano II sobre a Igreja: “abrem um amplo espaço à participação dos leigos, de quem definem a específica responsabilidade na Igreja” (JOÃO PAULO II, 1994, p.14). A proposta indicava a fase preparatória, no qual, a Igreja deve buscar unidade e centrarse nas questões morais que surgem do secularismo, por meio, do Filho, Espírito Santo e Pai, recordando a proposta Eucarística. Se por um lado o arcebispo justifica a realização do Hallel em Maringá por meio da carta papal, principalmente na tentativa de direcionar a quem seria direcionado o público, nesse caso a juventude, por outro lado ao narrar sobre onde e como foi inspirado o Hallel o arcebispo escreve:

Surgido na cidade de FRANCA-SP, em 1988, quis um grupo de jovens daquela cidade paulista propor â juventude, nos moldes do "Rock in Rio", na época, mas com uma concepção diferente, uma maneira nova e clara de Evangelização. Crescendo sempre em interesse e número de participantes, o Hallel 1994, em Franca, reuniu 40.000 pessoas (DOM JAIME, 1995, p. 2).

O primeiro Hallel no Brasil foi concebido na cidade de Franca-SP, em 1988. Andre Luis Centofante Alves (2016) discorre o seguinte:

Sua história iniciou-se no ano de 1988, quando um grupo de pessoas pertencentes ao movimento religioso Renovação Carismática Católica (RCC), ligado à Igreja Católica Apostólica Romana, decidiram realizar um evento REVISTARELEGENSTHRÉSKEIA - 2019 - UFPR 
musical para comemorar os dez anos da RCC na cidade de Franca, no Brasil. A ideia era organizar um evento similar ao Rock in Rio, festival internacional de música, realizado pela primeira vez no país em 1985, na cidade do Rio de Janeiro. Uma comissão de caráter informal criada por alguns líderes, entre jovens e adultos da RCC, e coordenada pela Sra. Maria Theodora Lemos Silveira, conhecida por Lolita, ficou responsável por conceber o evento, sem qualquer planejamento administrativo financeiro prévio. O primeiro Hallel aconteceu por conta da intuição e abnegação desse grupo. Cabe esclarecer que a palavra Hallel deriva do hebraico e significa cânticos de louvor a Deus (SILVEIRA, apud ALVES, 2016).

De acordo com Silveira (2007), Lolita visualizou muitos e muitos jovens ao ar livre, curtindo música de conteúdo espiritual. Seria um evento para jovens, como o Rock in Rio, porém, apresentando proposta de evangelização por meio da música, com mensagem diferente do evento original, ou seja, uma experiência de paz, de fé e de amor. Surgiu, assim, o evento de música Hallel - Som e Vida. Evangelizar aqui ganha significado enquanto processo de transformação na consciência individual e coletiva das pessoas, na atividade que elas exercem e no meio em que se encontram, em busca de qualidade de vida pessoal e comunitária, segundo a dimensão física (ALVES, 2016).

Nos jornais o Diário um dos principais indicadores sobre o que as pessoas podem esperar do Hallel é de que foi inspirado do Rock in Rio, ou seja, é um evento que terá característica de um festival de música, com palcos, bandas, shows, músicas. O narrar o Hallel nos parece aqui o relato do viajante de Hartog (1999) que na busca por descrever o mundo do outro busca traduções a que possa fazer-se ser compreendido. Segundo o autor, "dizer o outro é enuncia-lo como diferente" (HATORG, 1999, p.229). Os relatos de viajantes são narrados por meio da ótica comparativa do que o narrador já viu e vivenciou. Mesmo sendo, algo jamais visto, os viajantes "traduzem" o que é visto com elementos já constituídos e presentes em sua realidade, podendo dizer que é diferente ou semelhante a coisas que já viram. Ao descrever o visto, por vezes, se direciona aos seus, ou seja, essa tradução é realizada para que se torne palpável e compreensível na sociedade a que pertencemos.

Ao mesmo tempo em que há uma constante tentativa de assimilar o Hallel de Maringá sendo um evento inspirado num megaevento de rock, há uma constante enunciação sobre a diferença, pois o Hallel se trata de um evento que transforma, evangeliza, um local para encontrar o sagrado. Como poderemos perceber nos seguintes fragmentos sobre o Hallel o primeiro publicado em 2000 e o segundo em 2005:

Cerca de 50 mil pessoas devem participar, neste domingo, durante todo o dia, do Hallel 2000, um dos maiores eventos de evangelização do país, só superado pelos de Brasília (250 mil pessoas em 1999) e de Franca, no interior de São Paulo, onde a ideia surgiu em 1990. 
Caravanas de estados vizinhos, das cidades da região e de outros municípios paranaenses devem lotar as dependências do Pavilhão Internacional do Parque de Exposições Francisco feio Ribeiro desde as primeiras horas da manhã, segundo preveem os integrantes do Projeto Mais Vida, promotor do evento.

[...]

Inspirado, ao nascer, no megaevento do Rock mundial, o Rock in Rio, realizado em duas edições em meados da década de 80 , o Hallel - no entanto - optou por um vertente centrada nas questões de fé, da caminhada com Deus, na espiritualidade, na formação cristã e humana, explicam seus organizadores. Trata-se, portanto, de uma festa ecumênica, aberta a todas as pessoas, de todas as religiões.

A chave para o sucesso do Hallel parece ser exatamente esta: a capacidade de festejar a fé, a espiritualidade, com uma abordagem atualíssima, onde a música, o teatro, a dança, os shows e as orações se entrelaçam em harmonia, reforçando a integração, a solidariedade, a generosidade, promovendo- enfimuma renovação interior dos participantes. Algo como terapia em grupo, que se orienta pura a plenitude do amor cristão. (ROCHA, 2000, p. 10)

Mais de 100 mil pessoas transitaram no Parque de exposição em Maringá este final de semana, quando rolou a $12^{\mathrm{a}}$ edição do Hallel na cidade. Essa palavra, de origem aramaica, significa 'Aleluia' e já diz tudo: o encontro, organizado pela Igreja Católica, gira em torno de cântico em louvor a Deus.

O Hallel surgiu em Franca (SP) em 1988, idealizado por um grupo de jovens católicos que, inspirados em grandes eventos de massa e shows de rock, resolveram promover um evento com uma proposta muito clara de evangelização, Nessa última edição em Maringá, além de padre Zezinho, Celina Borges, e cantores de Deus e vários outros músicos de renome no cenário cristão, os roqueiros Wilson Rocha e Rosa de Saron mostraram que a fé pode ser muito bem adaptada e até difundida com ritmos 'pesado, como o heavy metal.

[...] (O DIÁRIO DO NORTE DO PARANÁ, 2005, p. D8).

Ao observar essas matérias sobre o Hallel de Maringá-PR é possível perceber que por se tratar de uma manifestação nova na cidade o evento é descrito como algo "maravilhoso" o "thôma", um momento a ser visto e vivenciado, para tanto, a tradução que se têm do evento com algo que possivelmente os leitores já viram o Rock in Rio, e mesmo que já constituído o evento na cidade, a referência ao festival de rock ainda é enfatizada. Hartog (1999) se refere ao "thôma" quando se trata do viajante relatando algo inusitado, curioso e diferente criando expectativas ao leitor do que foi visto é algo "maravilhoso". Nesse sentido, o Hallel por meio desses relatos é um evento a ser vivido, apenas aquele que vê, vivência o evento é capaz de perceber esse "maravilhoso".

Outro autor que contribuí com apontamentos sobre o caráter convidativo daquilo que é desconhecido é Rudolf Otto (1992), diferindo-se de Hartog (1999) que trata sobre os relatos de viajantes. Otto (1992) tece seu estudo sobre a experiência religiosa. Um dos aspectos a que Otto nos chama atenção é o: “Conceito de mistério designa unicamente o que está escondido, a saber, REVISTARELEGENSTHRÉSKEIA - 2019 - UFPR 
o que não é manifesto, aquilo que não é nem concebido nem compreendido, o extraordinário e o estranho, sem indicar com precisão a qualidade" (OTTO, 1992, p.22). Viés esse que nos possibilita compreender o relato do segundo Arcebispo de Maringá Dom Murilo Krieger (19972002) o jornal, publicado em 2001, na página 03 o Hallel 2001 é convite a alegria, diz dom Murilo:

Segundo o arcebispo, mesmo sendo aberto para todas as idades, o público do Hallel, na sua grande maioria, é composto por jovens. Um dos fatos que levam a isso, são as inúmeras bandas de música gospel, que se apresentam durante todo evento. Dom Murilo comentou que muitos jovens, desligados da fé, são tocados durante o encontro. "Ninguém passa pelo Hallel, sem ser tocado de alguma maneira", alertou.O arcebispo frisou que a principal marca do Hallel é a experiência de uma fé alegre. De acordo com ele, durante todo dia as pessoas que passeiam pelo parque são convidadas a alegria [...] (FRAGA, 2001, p.3).

A frase: "Ninguém passa pelo Hallel, sem ser tocado de alguma maneira", reforça a ideia de que há manifestação do sagrado no evento, e partindo do pressuposto de Otto (1992) o mistério do sagrado não é algo que cause apenas espanto, é também maravilhoso, assim: “Ao lado deste elemento perturbador aparece algo que seduz, arrasta, arrebata estranhamente, que cresce em intensidade até produzir o delírio e o inebriante; é o elemento dionisíaco da acção do numen. Chamamos-lhe o "fascinante" (OTTO, 1992, p.50). Perturbador, pois é algo desconhecido que não se pode explicar com exatidão, o sagrado só pode ser entendido se experienciado, segundo o autor. Além disso, o ser tocado de "alguma maneira" sugere as particularidades da vivência dessa experiência religiosa.

Desse modo, ainda podemos perceber por meio de Otto (1992) que o uso da música como expressão do sagrado: "Provoca uma alegria e uma felicidade, um sonho e um arrebatamento, uma tempestade e uma agitação no espírito, sem que o homem possa dizer ou que um conceito possa explicar em que consiste realmente aquilo que, na música, nos comove dessa maneira" (OTTO, 1992, p.71). A exemplo, Dom Jaime menciona:

Etimologicamente, a palavra vem da língua hebraica onde o louvor é traduzido de forma mais característica como "HILLEL". É uma explosão de hinos e cantos de louvor com o qual se designava, na antiga sinagoga, um grupo de Salmos (Sal 113-118), os quais se utilizavam especialmente em circunstâncias solenes e festivais. O mesmo se vê na tradição rabínica, de um "grande" Hallel. Cantavam-se salmos, na alegria e nas tristezas, mas sempre no louvor a YAHVEH, o Deus supremo, AQUELE QUE É, o louvor a um Deus VIVO. (DOM JAIME, 1995, p. 2, grifo nosso). 
Percebe-se que o nome do evento sugere essas sutilezas do espírito, seja em aspectos alegras ou de dor, e a música é um instrumento da manifestação do sagrado. Apesar do evento contar com diversas atividades a música e os shows são os que possuem maior destaque nas notícias, considerando as palavras de Ziza, uma das atrações principais do Hallel em 2006: “A música é universal, independente da cultura. Quebra preconceitos" e ainda acrescenta as seguintes frases: "É uma forma simples de lidar com fé". "A música é um estímulo evangelizador, mas a evangelização implica em conhecer um pouco mais. A música tem um papel de convidar" (MASSALI, 2006, p.D2).

Apesar de serem citadas as bandas e atrações do Hallel de Maringá no O Diário a partir de 1996, apenas em 2006 são realizadas publicações com entrevistas dos artistas, das bandas e das principais atrações, tal como vimos nos fragmentos acima que citam Ziza. Nesse mesmo ano ocorre uma entrevista com Pe.Zezinho com o título I Hallel-Um padre multimídia ${ }^{10}$ a que é descrito sua participação ativa nos meios de comunicação, na TV Século XXI, na internet, programas de rádio, enfatiza Pe. Zezinho para Fábio Massalli: “"A Igreja logo entendeu que a música é subsídio da evangelização, mas não é o único', disse. 'Do prato que o povo merece, a música é a sobremesa, não pode ocupar o lugar da pregação. Eu canto porque sou padre, não sou padre porque canto. A canção não me fez padre"” (MASSALI, 2006, p.D-3).

As publicações com ênfase nos padres midiáticos se repetem em $2008^{11}$ e 2015 com Pe. Reginaldo Manzotti, em $2016^{12}$ com Pe. Periquito ${ }^{13}$. As publicações realizadas sobre a presença desses padres no Hallel e a visibilidade a que $O$ Diário dispõe para os mesmos, acompanha o crescimento de bandas católicas quanto dos padres cantores. Camurça (2009, p.60-61) aponta que em meados de 1989 havia uma ínfima presença da Igreja católica nos meios de comunicação de massa, já não podia constatar o mesmo passado 20 anos.

Assim como Pe. Zezinho, Pe. Reginaldo Manzotti ressalta que "a música é uma forma direta de comunicação com Deus porque ela atrai, encante, é bela e Deus se revela nela também. O sucesso da música católica é porque as pessoas estão sedentas de Deus e encontram na música uma forma de entrar em sintonia com Deus" (O DIÁRIO DO NORTE DO PARANÁ, 2008,

\footnotetext{
${ }^{10}$ MASSALI, Fábio. I Hallel - Um padre multimídia. In: O Diário do Norte do Paraná. Maringá. p. D-3, 02 de set. 2006.

${ }^{11}$ O DIÁRIO DO NORTE DO PARANÁ. Show da fé em Maringá. Maringá, p. D-1, 03 e 08 de nov. 2008.

${ }^{12}$ DONADIO, Rafael. Para abençoar 70 mil pessoas. In: O Diário do Norte do Paraná. Maringá, p. D-1, 07 de nov. 2015.

${ }^{13}$ BISCHOFF. Wesley. Décadas de música e fé. In: O Diário do Norte do Paraná. Maringá, p. D-1, 03 de dez. 2016.
} 
p.D-1). Corroborando para o que já pontuamos sobre a percepção da música como um meio de contato com o sagrado.

Visto isso, podemos considerar que essas narrativas sobre o Hallel, sobre os instrumentos e mecanismos utilizados no evento estão inseridos no contexto em que as novas comunidades que,

germinam a partir da experiência encantada em um mundo que valoriza decisões racionais. Seus membros frequentemente aludem à procura de preenchimento do 'vazio existencial que experimentavam' e de maior dedicação, defendem suas opções afirmando que 'na comunidade achavam o que almejavam' (CARRANZA; MARIZ, 2009, p.155).

Ao encontro de tal apontamento podemos citar Dom Murilo que expõe no $O$ Diário, "que o envolvimento dos cristãos em movimentos e pastorais faz parte do sentimento religioso. 'Os jovens estão em busca de outros valores. Eles estão cansados de propostas vazias. Querem encher o seu coração e valorizam a experiência da fé"” (MELLO, 1998, p.8).

\section{Considerações Finais}

As narrativas encontradas sobre o Hallel de Maringá, publicadas pelo O Diário do Norte do Paraná possibilita a compreensão de um contexto histórico na religiosidade católica na cidade. Os debates da Igreja católica direcionados aos jovens ganham intensidade a partir da década de 1970, o investimento em pastorais e movimentos leigos para que se crie um vínculo de identificação considerando a particularidade e necessidade de cada grupo, começa a ser um ponto estratégico da Igreja, e como pontuado no início do texto as concepções do leigo como o principal agente da "nova evangelização" legitima a realização de diversas práticas católicas no Brasil.

As primeiras publicações por meio desse veículo de comunicação apresentam um discurso atrelado a instituição e a proposta de legitimação do evento. Consideramos que os produtores desses discursos fazem uma leitura de uma dada realidade e produzem narrativas a que possam ser ao mesmo tempo apresentadas enquanto algo nova e instigante. Entretanto, quando se pretende algo novo é necessário que haja a possibilidade de que os indivíduos reconheçam e tenham a curiosidade de compreender e buscar esses novos mecanismos de evangelização. Pensar as narrativas construídas sobre o Hallel por meio do $O$ Diário é pensar também sobre uma "tradução", pois ao passo em os organizadores dizem que o evento reúne as 
mais variadas pastorais ainda não é palpável sobre o que possa acontecer no local, levando em consideração que cada movimento e seguimento da Igreja Católica pode possuir particularidades em suas práticas.

Os grandes festivais de músicas pós-final de 1969 são grandes motrizes de aglomeração de jovens. Ao esboçar que o evento surge em 1988 na cidade de Franca-SP e inspirado do Rock in Rio podemos identificar a narrativa do "curioso", pois jovens poderão estar em um local onde encontrarão músicas de gêneros como rock, pop que falam de Cristo, o secular e sagrado no mesmo local. Além disso, citar esse grande evento que ocorreu em 1985 e ficou conhecido mundialmente, possibilita uma assimilação mais eficaz de que Hallel também é um evento de música.

Não basta dizer que é um evento de música é necessário instigar, desse modo ao passo que se busca os shows, as atrações e pregações é apresentado que o evento transforma, o sagrado estará naquele local e apenas as pessoas que passam pelo Hallel sabem o que é essa experiência. Concluímos por fim, que as descrições sobre o Hallel no $O$ Diário se assemelha ao que Hartog (1999) identifica como a narrativa do "maravilhoso", considerando que o uso do nome de um evento secular de música é de fácil reconhecimento para os leitores. Entretanto sem perder os aspectos da manifestação do sagrado, considerando que as narrativas constantemente apontam o caráter evangelizador da Igreja católica.

Nesse contexto, é válido pontuar que ao pensar as narrativas sobre o Hallel no O Diário essas se constroem com base no discurso da Igreja católica, que opta por descrições a que passo por seu crivo. O que nos leva a pontuar que a escolha sobre o "maravilhoso" também é um olhar lançado por uma determinada ótica, assim, como o viajante que constrói e filtra sua narrativa, que traduz sua viagem correlacionado a sua perspectiva sobre o visto e sobre o que deve ser visto.

Como observado apesar das atrações, serem citadas desde 1996 no O Diário era mais enfático uma visão mais geral sobre as atividades propostas nos módulos, sobre a programação e as principais atrações musicais, apenas em 2006 é que podemos ver a narrativa dos próprios artistas, e/ou a publicidade realizada sobre esses. Mas esses discursos ainda carregam a percepção de como essas manifestações religiosas por meio da música é constituída pelo "maravilhoso", pois a música é um instrumento que possibilita acessar o sagrado e senti-lo ao modo que causa o fascínio de estar no Hallel. 
Ao considerar tais questões não podemos perder de vista que o espaço a que os padres midiáticos, os músicos católicos começam a receber nos jornais também se deve ao crescimento desses no cenário religioso católico, principalmente por meio das mídias televisivas, internet, rádios. Nesse sentido, o Hallel de Maringá é um espaço em que reúne pastorais, movimentos, grupos da Igreja católica que tanto apresentam atividades, quanto consomem. Tal configuração pode ser percebida num contexto de um catolicismo de novas comunidades.

\section{Fontes:}

BISCHOFF. W. Décadas de música e fé. In: O Diário do Norte do Paraná. Maringá, p. D-1, 03 de dez. 2016.

DOM JAIME. I Hallel de Maringá, Maringá, In: O Diário do Norte do Paraná. p. 4, 29 jul.1995.

DONADIO, R. Para abençoar 70 mil pessoas. In: O Diário do Norte do Paraná. Maringá, p. D-1, 07 de nov. 2015.

FRAGA, C. Hallel 2001 é um convite a alegria, diz dom Murilo. In: O Diário do Norte do Paraná. Maringá, p. 03, 01 de set. 2001.

MASSALI, F. I Hallel - Um padre multimídia. In: O Diário do Norte do Paraná. Maringá. p. D-3, 02 de set. 2006.

MASSALI, F. I Hallel - Um padre multimídia. In: O Diário do Norte do Paraná. Maringá. p. D-3, 02 de set. 2006.

MELLO, L. Hallel deve atrair 30 mil pessoas hoje. In: O Diário do Norte do Paraná, Maringá, p.8, 05 de set. 1998.

O DIÁRIO DO NORTE DO PARANÁ. Hallel, Maringá, p. 02, 30 jul.1995.

O DIÁRIO DO NORTE DO PARANÁ. Festa da fé, Maringá, p. 01, 03 set. 2000.

O DIÁRIO DO NORTE DO PARANÁ. Hallel, Maringá, p. 04, 01 set. 2005.

O DIÁRIO DO NORTE DO PARANÁ. Show da fé em Maringá. Maringá, p. D-1, 03 e 08 de nov. 2008.

O DIÁRIO DO NORTE DO PARANÁ. Show da fé em Maringá. Maringá, p. D-1, 03 e 08 de nov. 2008.

O DIÁRIO DO NORTE DO PARANÁ. Uma presença constante, Maringá, p. D-2, 03 e 04 set. 2006. 
ROCHA, E. Hallel deve receber 50 mil pessoas hoje. In: O Diário do Norte do Paraná. Maringá, p. 10, 03 de set. 2000.

\section{Referências}

ALVES, A. L. C. A gestão social na atividade educacional religiosa: o caso da Hallel Escola no Brasil. 2016. 201 f. Tese (Doutorado em Serviço Social) - Faculdade de Ciências Humanas e Sociais, Universidade Estadual Paulista “Júlio de Mesquita Filho”, Franca, 2016.

ARAÚJO JR, O. R.; PREISS, L. Hallel Maringá. SILVEIRA, Maria Theodora Lemos. Introdução. In: (Org.). Hallel - som e vida: 20 anos! uma história a ser contada e cantada. Franca: Hallel, p.135-138, 2007.

BARBOSA, Everton; PEÑA, Luciana. Jaime uma história de fé e empreendorismo. DNP Editora, Maringá, 2011.

CAMURÇA, M. A. Tradicionalismo e meios de comunicação de massa: o catolicismo midiático. In: CARRANZA, B.; MARIZ, C.; CAMURÇA, M. (Orgs.). Novas comunidades católicas: em busca do espaço pós-moderno. Aparecida: Ideias \& letras, 2009, p. 59-78.

CARRANZA, B.; MARIZ, C. Novas comunidades católicas: por que crescem? In:__(Orgs.). Novas comunidades católicas: em busca do espaço pós-moderno. Aparecida: Ideias \& letras, 2009, p. 139-170.

CRUZ, H. de F.; PEIXOTO, M. R. C. Na Oficina do Historiador: Conversas Sobre História e Imprensa. Projeto História: Revista do Programa de Estudos Pós-Graduados de História, [S.1.], v. 35, dez. 2007. ISSN 2176-2767. Disponível em: <https://revistas.pucsp.br/index.php/revph/article/view/2221>. Acesso em: 10 abr. 2018.

HARTOG, F. Uma retórica da alteridade. In: O Espelho de Heródoto: Ensaio sobre a representação do outro. Editora UFMG, Belo Horizonte. 1999.

IBGE. Censo demográfico 2010: Disponível em: https://cidades.ibge.gov.br/brasil/pr/maringa/panorama. Acesso em: 11 de out, de 2019.

OTTO, R. O sagrado. Lisboa: Edições 70, 1992. 